\title{
Discourse Analyses of Chinese Visiting Professors at Canadian Universities: Adaptation and Transformation
}

\author{
Lin $\mathrm{Ge}^{1}$ \\ ${ }^{1}$ Faculty of Education, University of Regina, Regina, Canada \\ Correspondence: Lin Ge, Faculty of Education, University of Regina, Regina, Canada. ON., S4S 0A2, Canada. \\ Tel: 1-306-216-7685. E-mail: gelinsy01@gmail.com
}

Received: December 6, 2018

doi:10.5539/ies.v12n4p87
Accepted: January 9, $2019 \quad$ Online Published: March 20, 2019

URL: https://doi.org/10.5539/ies.v12n4p87

\begin{abstract}
Chinese visiting professors, as Chinese university educators, are playing both practitioners and conformists in adapting to Western teaching perspectives and pedagogies while maintaining Chinese teaching beliefs. This study attempts to understand the international university experiences (Canada) of Chinese visiting professors. Arguably, Chinese visiting professors might potentially engage in programs aimed at providing an advance preparation for Chinese international graduate students, furthering their successful transition in study abroad. This paper is oriented to a post-structural paradigm in order to remain open to the attitudes, beliefs, and values of participants. The findings of a discourse analysis of Chinese visiting professors at a Canadian university are presented. The findings disclosed specific accounts as provided by this research group (i.e. dual academic and teaching experiences, and bicultural experiences in Chinese and Canadian universities). Using the findings, recommendations were made in bridging potential challenges to studying abroad. Specific to this task is the construction of an in-country program aimed at preparing Chinese undergraduate and graduate students for study overseas (specifically in Canada).
\end{abstract}

Keywords: Chinese international graduate students, Chinese visiting professors, discourse analysis, transitive preparation

\section{Introduction}

With the trend of educational globalization, a host of international students make difficult decisions in coming to foreign universities such as U.S and Canada for their higher education. In particular, the striking development of Chinese reform and "opening-up" policy dramatically nudged the outflow of the younger generation for studying further. There were about 340,000 of them to seek higher education in America in 2018(around 30\% of all foreign students) (Zhou, 2018). In Canada, Chinese students represented the largest percentage (34.1\%) of international students attending post-secondary institutions (Statistics Canada, 2016).From 2015-2016 to 2016-2017, international students from China increased by 5,211 (+8.9\%) (Statistics Canada, 2018). For example, at the University of Regina, of about 1900 international students in 2018, approximately $44 \%$ of those are from China (UR International, 2018).

However, the transition into foreign university studies is an overwhelming challenge, even for the most talented international students. In terms of Chinese international graduate students, it needs to be noted that the group has left behind familiar university surroundings and supports associated with their country of origin while they need adjusting to a Western educational system and wrestling with Western cultural (Yang, 2010; Zhao \& McDougall, 2008). Once they fail to make adjustments necessary, it could mean "losing face" at home, shaming their families. These situations suggest a need for further research into how Chinese international graduate student transition can be made more smooth and successful.

University educators, as pivotal agents in the educational process, should be viewed as the main promoter and practitioner of higher education. They often are equated to schooling in the views of students, parents, and community members. Nevertheless, in most cases, these educators occupy a complicated and contradictory position because they not only represent the school and authority to parents and students, but also have to be subordinate to fixed teaching programmes and overarching educational hierarchies(subjecting to principals and senior administrators) (Wotherspoon, 2014). They are expected to be advocates for educational innovation and pedagogic transformation, but they have to yield public scrutiny regarding what and how they teach as well as 
"their overall moral character" (Wotherspoon, 2014, p. 160) about what or how they should teach for students. In the case of Chinese higher education, arguably, university educators are conditioned to lecture and assert their authority, transferring fixed knowledge and skills as the most proper teaching method. Therefore, it is crucial to excavate whether Chinese university educators might work to assist the transition of potential Chinese international graduate students through their teaching practices.

Currently, internationalization of higher education has been suggested and implemented as an approach to cope with the trend of educational globalization (Altbach \& Knight, 2007; de Wit, 2002; Knight, 2008). Internationalization of higher education is defined as "the process of integrating an international, intercultural or global dimension into the purpose, functions or delivery of postsecondary education" (Knight, 2003, p. 2). In response, many countries have dispatched a host of university educators as visiting professors to go abroad for engaging in a short-time visit and exchange. China, as the biggest developing country, is no exception from this trend. In 2018, the Chinese government planned to send about 3,500 senior researchers and visiting professors to the countries with developed education, science and technology, well-known institutions, research institutes, and laboratories (Chinese Scholarship Committee[CSC], 2017). The visiting period is usually in a range of 3-12 months. CSC sponsorship provides a number of required supports, including transportation, accommodations, and health care (CSC, 2017). Not surprisingly, international visits by Chinese university educators have increased in recent years, markedly outstripping other nations (Shimmi, 2014). For example, from 2006 to 2009, Chinese international professors traveling to the US increased from 1482 to 2792 (Shimmi, 2014). In Canadian universities, the number of Chinese visiting professors is also rising. At the University of Regina, there are about 58 visiting professors from multiple fields (90 percent of these professors are from China) (UR international, 2018). With a salient rise in Chinese visiting professors, they come into a greater exposure to Western ways, perspectives, and pedagogies.

As such, Chinese visiting professors are placed in binary dilemmas of the two aforementioned power relations. On one hand, the group needs to act on their lectures to normalize students in their home universities. On the other hand, they also have to discipline themselves in expected ways of host universities during their visit such as the seminar, presentation, individuality, and critical thinking. Such situations make the group witnessing adequately the contradistinction between the two educational ways and cultures. Therefore, this group is more likely to be drawn upon as an indispensable resource for the successful transition of future Chinese international graduate students.

In this study, the researcher is interested in a discourse analysis of Chinese visiting professors at the prairie university, the University of Regina, to uncover their discourses' construction and function, i.e., how are their discourses are put together, and what are gained by these construction; How accounts are constructed by the group based on their empiricist and contingent repertoires as constrained i.e. dual academic and teaching experiences, and bicultural experiences in Chinese and Canadian universities; How their experiences are valuable resources for the transition of future Chinese graduate students studying abroad.

\section{Literature Review}

\subsection{Studies Focusing on Chinese International Students}

Due to the one-child policy formulated during the past decades, as far as Chinese parents are concerned, offering sufficient financial support for their children to obtain higher education in international post-secondary institutions has become less difficult. Moreover, Chinese higher education was inclined to master basic knowledge instead of practical abilities, which compelled many Chinese parents to eagerly send their children in developed countries such as America and Canada for higher education (Chao, 2016). But, language acquisition is an obvious barrier for international students (Galloway \& Jenkins, 2005). To compensate many Chinese students focus on programs seen as less language based, such as science, engineering, and business, circumventing the arts or humanities (Canada Statistics, 2016). For example, many Chinese students consider science and engineering faculties as better choices in consideration of future employment (Ortiz, Chang, \& Fang, 2015). Traditional educational history has also mentioned to play into adaptation and success in Chinese international students. Chinese teaching seems to tend to teacher-based lecture and rote memorization (Gu, 2006) so Chinese students often figure out it difficult to speak out and present in the Western classrooms (Yang, 2010; Zhao \& McDougall, 2008). What is more, they have to face life pressures including their social life, housing and cultural shock in the new environment (Kuo \& Roysircar, 2004; Liang, 2003; Sam, 2001; Zhang \& Zhou, 2010). For instance, Chinese international students merely communicate with and seek help from Chinese friends rather than those students from other countries or the locality (Jiao, 2006).

All of the above studies attempt to identify and explain barriers and challenges of international students in a North 
American landscape. However, no literature has focused on how Chinese universities can engage in the transitive preparation of Chinese international graduate students before their study abroad.

\subsection{Research Concerning Chinese Visiting Professors}

A few studies on Chinese visiting scholars in North America mainly have focused on cultural barriers, language barriers, and academic adaptation (Shimmi, 2014). To be more exact, firstly, for the successful adaptation of Chinese visiting scholars, language appears to be a prioritized factor. Chinese visiting scholars in Canada experience their barrier in communication (Zheng \& Berry, 1991). Specifically, Chinese visiting scholars emphasize more a need in oral English development, while Chinese graduate students highlight the needs for both oral English communication and writing skills (Sun, 1987). Secondly, Xue et al. (2015) reveal the strategies used by Chinese visiting professors for "academic socialization includes motivation, social networking development, academic recognition, goal orientation, and community involvement" (p.1) and implications for Chinese Scholarship Committee (CSC) policymakers, international visiting scholars, and researchers. In addition, previous studies have discussed some psychological issues of Chinese visiting professors in relation to their adaptation (Li \& Chen, 2017). Most visiting professors usually take their families to the host countries, which renders Visiting professors facing extra psychological stresses in adjusting to Canadian culture and displayed struggles in integrating into the local environment (Li \& Chen, 2017). Chinese visiting professors are inclined to accept passively when they experience adaptation stresses (Zheng \& Berry, 1991). A Chinese visiting professor's endeavour for pursuing open-mindedness and positive attitudes is able to help him or her adjust to a new academic environment (Zhao \& McDougall, 2008). In addition, Huang (2015) also presents that improving intercultural education at Chinese institutions entails a positive implication based on German experience.

However, these studies have specifically viewed Chinese visiting professors as underlying practitioners relating to the successful transition of Chinese international graduate students. Therefore, the present study attempted to bridge the gap because the researcher aimed at exploring how these visiting professors' experiences could prove fruitfully in establishing a transitive preparation for students planning to study abroad continually.

\section{Methodology}

The theoretical orientation of the article is heavily guided via post-structural theory. A Post-structuralist paradigm has a strong emphasis on investigation of discourse, which shows power-knowledge relationships (Savin-Baden \& Major, 2013). It also stresses that the meanings entail "not only in particulars words but in the relations of words to each other" (Agger, 1992, p.93). In light of the paradigm, it confirms the researcher that discourse analysis can be employed as the methodology to guide the action-based study. It is an effective approach to analyze written, vocal, or sign language use, or any significant semiotic event (Tannen, 2012). The objects of discourse analysis are multiply underscored in the coherent sequences of sentences, propositions, speech, or turns-at-talk (Tannen, 2012). Discourse analysis not only studies language use 'beyond the sentence boundary' but also analyzes how language use shape identities, interpretations, and actions (Gee, 1999). Discourse analysis serves as revealing socio-psychological characteristics of a person/persons rather than text structure (Yatsko, 2013). In the present study, discourse analysis serves to deconstruct Chinese visiting professors' discourses so as to better apprehend the international experiences (Canada) of the group and probe the implications of their experiences in improving the successful transition (academic, social, cultural) of future Chinese international graduate students.

\subsection{Data Collection Methods}

In the present study, semi-structured interviews were employed to collect data from participants. Arguably, participants' interpretations are usually more context-dependent and changeable than normally recognized. The use of interview data can help researchers obtain more authentic implication rather than coin definitive versions of participants' action or beliefs (Talja, 1997). Conducting one-on-one interview talks with Chinese visiting professors at the University of Regina based on some predesigned questions and their random utterances helped explore their visiting experiences, challenges, and thinking and understanding about their identity. As a discourse analysis used in the study, the participants were encouraged to fully speak out. All interviews were recorded by audio and transcribed closely in Chinese. After the confirmation of participants, the transcripts were verbatim translated into English to encode them. Interview questions focused on personal stories and related topics:

1) Why did you choose to visit a Canadian post-secondary institution?

2) What are some of your most memorable experiences (positive/negative) during this study period?

3) How do your past teaching experiences influence your academic experience in the new institution?

4) How do you view the difference between Chinese and Canadian post-secondary education? 
5) How do you plan to utilize these experiences in your home institutions?

6) How could you improve the successful transition (academic, social, cultural) of Chinese international students abroad?

Meanwhile, the researcher developed a one-hour group discussion recorded by a recorder without the researcher' participation, which avoided the intervention of researchers' discourses and facilitated the individualization of participants' discursive formation. The way allowed the researcher to explore new space for the emergence of some perspectives around the feasibility of drawing Western higher educational way into Chinese higher education, namely: do you think that it is feasible to employ Canadian universities' educational idea to Chinese higher education? If it is feasible, how can it embody in your pedagogy? If it is not feasible, what are the underlying resistances? During the process, these participants provided more authentic data for the researcher' discourse analysis and offered emerging insights into their given discourses. This verified further the researcher's assumption in the possibility of pre-preparation of transition of potential Chinese international graduate students before their going abroad.

\subsection{Data Analysis Methods}

In light of the research questions and research purposes, the researcher selected a series of keywords or phrases from the transcripts that were the most important. Then, the researcher thought about what "situated meanings these words and phrases seem to have" in these research data; the researcher also thought about "the social language and discourses that appear to be relevant" (Gee, 1999, p. 97). In light of Gee (1999), the researcher was considering what and how social activities and socially-situated identities were being enacted or recognized in these research data (recognized by participants and the researcher as an analyst).

After the aforementioned initial reflections, the researcher asked herself about six tools of inquiry questions about each of the seven building task, i.e., "significance, practices, identities, relationships, politics, connections, and sign systems and knowledge" listed by (Gee, 1999, pp. 140-141). Gee devised these questions to help researchers conduct an ideal discourse analysis. Then, the researcher took note and reflected on their answers to these questions, guided by the themes or questions with which the researcher has started in order to confirm whether the research questions have been answered or any others emerge. Finally, the researcher systematically organized all her analyses and illuminated the main points she has chosen to address in the study (Gee, 1999).

\subsection{Study Participants}

For this study homogenous sampling was used as these Chinese visiting professors possess generalizable traits (i.e., language, educational background, all visiting at the university). The researcher collected qualitative research data from 10 visiting professors who are from 10 Chinese universities located in Southern and Northern provinces respectively in China, and with different academic fields and visiting time in the age range from 30-50 years. The researcher emailed or handed out participant consent forms to them. Based on the consideration of gender difference and ethics, they were equally divided between males and females (Table 1). During the investigation, the researcher respected their individual privacy and preserved participants from any harmful results so all participants were reported in pseudonyms. 
Table 1. Sample characteristics

\begin{tabular}{|c|c|c|c|c|c|c|}
\hline Academic fields & Age & Gender & Technical post & $\begin{array}{l}\text { Periods of } \\
\text { Visits }\end{array}$ & $\begin{array}{l}\text { Accompanied Family } \\
\text { members }\end{array}$ & $\begin{array}{c}\text { The timing prior to the } \\
\text { research }\end{array}$ \\
\hline Petroleum Engineering & 40 & Male & $\begin{array}{l}\text { Associate } \\
\text { professor }\end{array}$ & One year & Child and wife & One year \\
\hline $\begin{array}{c}\text { Mathematics \& } \\
\text { Computer Science }\end{array}$ & 43 & Female & Professor & One year & Child & One year \\
\hline Mathematics \&Physics & 40 & Male & $\begin{array}{l}\text { Associate } \\
\text { professor }\end{array}$ & One year & Child & One year \\
\hline $\begin{array}{l}\text { Uncertain Data } \\
\text { Management }\end{array}$ & 41 & Female & $\begin{array}{l}\text { Associate } \\
\text { professor }\end{array}$ & One year & Child & One year \\
\hline Computer Science & 35 & Male & Professor & One year & None & About two months \\
\hline Education & 42 & Female & $\begin{array}{l}\text { Associate } \\
\text { professor }\end{array}$ & One year & Child & About three months \\
\hline $\begin{array}{l}\text { Oil and Natural Gas } \\
\text { Engineering, }\end{array}$ & 34 & Male & Lecturer & One year & None & About two months \\
\hline Geology & 37 & Female & $\begin{array}{l}\text { Associate } \\
\text { professor }\end{array}$ & Six months & Child & About Five months \\
\hline Sociology & 40 & Male & $\begin{array}{l}\text { Associate } \\
\text { professor }\end{array}$ & Six months & None & Six months \\
\hline English & 49 & Female & $\begin{array}{l}\text { Associate } \\
\text { professor }\end{array}$ & Three months & None & About three months \\
\hline
\end{tabular}

\section{Findings}

As mentioned above, the data sources included semi-structured interviews and focus group transcripts. These data were analyzed and coded based on the consideration of the difference in either the content or form of participants' accounts and consistency (Gee, 1999). What is more, the researcher was concerned more with functions and consequences of informants' talks to search for the linguistic evidence of her assumption.

\subsection{Findings from Interviews}

\subsubsection{Purposes of Visit: the Latent Impact of Chinese Educational Culture}

According to the analysis with the interplay of participants 'talk and their context, the researcher reflected on the building task 2, namely: "How are situated meaning, social languages, figured worlds, intertextuality, discourses, and conversation being used to enact a practice or practices in context?" (Gee, 1999, p. 140) That is, socially-situated practices are mutually constructed in the interviews.

\section{- Professional development}

The aims related to individuals' professional development were overwhelming including advancing their research, developing scholarly networks, and improving English language skills for academic purposes. Although these participants used individualized language, their empiricist repertoires and the disciplinary power of their home universities seemed to potentially effect on their visit. For example, as White (male) said,

I visited here due to two reasons. Mainly, my home university has a strict requirement that if we want to be awarded as a professor, we must have three or above visiting experience abroad. Therefore, we must go abroad to visit. Secondly, except for the requirement, I feel this is a good opportunity to improve myself. But it doesn't mean that everyone can get the permission to go abroad. Each year, every faculty only has two or three candidates who can be allowed to visit abroad. Undoubtedly, um, remarkably outstanding ones can be given this opportunity in advance. Before coming here, I also had some ideas about what I should do during this year because my home university will have a rigorous evaluation to my visit after going back to China including my experience and something seeing and hearing.

Throughout the interview, his discourse seemed to embody a culturally universal sensibility within Chinese universities. He utilized some absolute lexical items such as "strict requirement", "must", "only", "undoubtedly", "remarkably", and "rigorous", which suggested his visit was influenced by his home university to a large extent. Moreover, he used a more affirmative language with little hesitation, i.e., "Undoubtedly, um...remarkably outstanding ones can be given this opportunity in advance" to express the significance of professional improvement during his visit. 


\section{- $\quad$ Family experiences}

Most participants had relatives accompanying them during their visit. Therefore, they reported family-related objectives such as providing international experiences for their children. Due to Chinese parents' relatively solidified social identities and family educational notion (monopolizing anything for children), these visiting professors as parents unavoidably were influenced in their family education. As Smile (female) mentioned,

I have the opportunity to take my child abroad to accept short-term study, feel the education of foreign primary and secondary schools, appreciate the exotic customs and culture, and broaden his horizon. In particular, Chinese people value children's growth so to me, my son's study is more important than that of my own.

Her discourse entailed empiricist subjectivism (Burton \& Carlen, 1979), namely: she subjectively affirmed the advantages of Western education. She used some stressing lexis and sentences such as "in particular", "more important", "Chinese people value children's growth", which implied her main visit purpose disciplined by her localized educational belief.

\section{- $\quad$ Teaching}

Only three male participants signified the intention of improving teaching and intended to observe or to be involved in teaching and instruction at the host university. They could observe courses and curriculum structures at the host university but the observations were not so frequent (merely two or three times during their visit). According to their talks, improving teaching skills usually were posited on a subordinate position with the momentary standstill and hesitation, which appeared to reiterate that learning new teaching practices and bringing them into their following teaching were not viewed as an imperative mission for themselves and their home universities. For instance, White (male), a professor, signified: "Um.....actually, I almost did not learn foreign universities before coming here including teaching ways and research ways. Um....I try to figure out if these aspects would have positive use to my following teaching. Anyway, I want to learn something and practice my English". In his narrative, it could be figured out that improving teaching was a contingent, personal, and sudden realization for him because he hesitated a moment and used some assuming lexis such as "almost" "try"," if", "anyway". Also, $W u$ (male) said,

Um... in term of teaching in China, firstly, um, the most direct way is that it is possible to introduce the bilingual teaching method. This is not a big problem. Secondly, that is, I found out the way of undergraduate teaching here is similar with that of China. Therefore, it is not so necessary to draw upon. In the aspect of graduate students, they just pay more attention to assignments and the depth of assignments. In this part, we could absorb a good aspect. Currently, I came here just for few months so I learned a little bit.

$W u$ organized his oral text in a neutral manner. He used more neutral words such as "possible", "bilingual", "similar", and "not so necessary", "could" to embody his acceptable extent of Western higher education. He also emphasized that "I came here just for few months so I learned a little bit", which means in turn, he appeared to have an attempted to veil his opinion based on the interference of his empiricist repertoire.

\subsubsection{Cross-Cultural Strategy: Outside Acceptance and Inside Withdraw}

In this part, the researcher considered the whole interviews and reflected on the building task 6 mentioned by Gee (1999), namely: "In any situations, things are connected or disconnected, relevant to or irrelevant to each other, in certain ways."(p. 185)In doing so, it can figure out how these participants face cultural barriers as connected and relevant to each other in their world and how they address these barriers. The researcher found almost all participants held positive attitudes and tried to make a connection or relevance to the new cultural environment. However, from their narratives, it indicated that the difficulty of cultural contact faced by them existed imperceptibly. Meanwhile, they signified apparently a negative mood to language barriers. As White (male) mentioned,

I feel that at the beginning, I need to adapt to the new environment. Then, um.......group life. I have to cook but fortunately, I can cook in China so it is ok for me. Um, transport is not so convenient that we have to buy a car to go to university. I do not always to go to the university, occasionally; I go and have classes because I did not find any relevant class in my field in this semester. Maybe, in next semester, I will choose some classes to have. I like staying alone so I can think something. I have few communications with local people because my friend circle mainly contains Chinese people. I only participated in an International night at the university.

In his oral text, he used more passive words or phrases to express his acceptance to the current environment such as 
"need to", "liking staying alone", and "have to "and so on. On the other hand, his cultural barriers also were insinuated because he always had many hesitations and pauses with some disconnected sentences such as "Um", "occasionally", "I only participated in an International night at the university". Also, $\mathrm{Wu}$ (male) expressed more obvious language barrier that

Basically, I cannot communicate with them because I cannot understand what they say. The accent here is totally different with what I already learned about English in China. Therefore, I am still stuck in language barriers. In terms of academic aspect, the university is not better than Chinese universities in technology. But their students' experimental skill is better than that of Chinese universities. Also, they have few trivial things such as filling in forms and writing documents except for their researches. Therefore, in China, we do not have enough time to concentrate on our studies. In addition, routine presentations are the good platforms to communicate research results and processes between teachers and students.

$W u$ signified his acceptance and appreciation to the culture of the host university with fraternal critiques (Burton \& Carlen, 1979) such as "but their students' experimental skill is better than that of Chinese universities" and "routine presentations are the good platforms to communicate research results and processes between teachers and students". Meanwhile, his language barrier seemed to make him be frustrated based on these words such as "basically", "totally", and "be stuck".

\subsubsection{An Entangling Attitude to the Transition of Chinese International Graduate Students}

In terms of this aspect, the researcher considered how social significant identities were mutually constructed in language and what this had to do with situated meanings, social languages, figured worlds and discourses. Based on participants' conventional beliefs, solidified social identities and disciplined power relationship between teachers and students in their home universities, it engendered an entangling attitude to the transition of Chinese international graduate students, i.e., they did not view language as the main barrier and even thought Chinese students did not have an obvious barrier. One the other hand, they suggested heavily that Chinese students were meeting a cultural barrier to a large extent. Garry (male), a dean and professor, said,

I think the transition does not have an obvious barrier. Because many graduate students have opportunities to participate in a one-year joint training program of Western universities. But Western universities emphasize more independence and autonomy. Students need to complete independently or have independent ideas or perspectives.

As a dean, he used more official language and cognitive statements (e.g., "I think.....") to argue that Chinese universities had been contributing to the transition of Chinese international graduate students such as "because many graduate students have opportunities to participate in a one-year joint training program of Western universities". Conversely, he also utilized academic-like lexical items i.e., "independence" and "autonomy" that were ignored relatively in Chinese universities to illuminate his worry of the transition of Chinese international students.

$J u d y$ (female) also mentioned in her oral text,

This transition is not easy. In my opinion, it mainly includes two aspects: learning methods and cultural differences. The learning methods are embodied in: Chinese students in the domestic study, the learning methods mainly emphasized the knowledge in an understanding and mastery degree. And Western universities emphasize extensive readings and thinking ability training. Therefore, Chinese students first need to adjust their study methods in advance. The cultural differences are mainly reflected on the Chinese students' habit of achieving good results through hard work and repeated practice with modesty and prudence without sufficient flexibility of thinking, communication skills, and expressing opinions in public

She employed some ability and constraint statements to indicate the main barriers facing during the transition with underlying reasons. In her interview, the two phrases, "learning methods" and "culture difference", were stressed and restated in order to indicate the entrenched difference between Chinese and Western universities protocols as the main factor influencing Chinese students' adjustment.

\subsubsection{Overwhelming Differences between Two Higher Education Models (Chinese and Canadian)}

As far as the topic was concerned, the researcher looked across the whole interview based on the consideration of "how are situated meanings, social languages, figured worlds, intertextuality, Discourses, and Conversations being used to build and sustain social relationships" (Building Task 4)(Gee, 1999, p.140). Throughout the interviews, participants indicated overwhelming differences including university management, curriculum designs, classroom 
teachings, teaching ideas, and the relationship between teachers and students. From their narratives, participants seemed to avow some advantages of Canadian higher education, i.e., "openness", "freedom", "flexibility", and "operability" and deficiencies of Chinese higher education, i.e., "conservative", "strict", "rigid", "one size fits all", and "fixed curriculum". However, their discourses seemed to be more contradictory and neutral due to the potential impacts of their previous power relationships. For example, Hao signified,

It is a mutual influence each other. In my home university, I am not willing to obey the conventional teaching methods because I dislike teaching students rigidly based on the fixed contents of curriculum that my students and I both feel bored. I always make some innovations. I think studying is more important than teaching. Moreover, Chinese universities restrict students strictly due to the Chinese national situation. As general teachers, our abilities are not enough to make a difference. But in my class, I hope I can give them a relatively free space. But I feel I am weak to do this. We are managed so strictly that we are observed by cameras without any right of teachers. Actually, I have little control over my class based on some invisible restriction. I only try my best to be clearer in a more flexible way. But the reality does not allow me to do so. It is difficult, really difficult.

Hao (male)'s language connected directly to the world "out there" (Gee, 1999, p. 187). He had a will to practice inter-cultural teaching but he still had to immerse himself into the power relationship with limited changes. He used some lexical items and sentences such as "really difficult", "mutual influences", "I have few controls to my class based on some invisible restriction", and "but the reality does not allow me to do so", which entailed his passive mindset and attitude.

\subsubsection{Application Strategies of International Experience in Home Universities}

In the interviews, the informants also reflected on how they would use the visiting experiences to their following work in home universities. Most of them seemed to have the utmost passion to elevate their teaching with what was learned in their host university pertaining to "progressive pedagogy", "public presentation", "seminar", "introducing overseas experience", and "bilingual teaching". They located academic improvement in a minor position such as "research attitude", "research direction", and "publication". Such situation exactly was opposite to the purpose part mentioned above, which embodied the contradiction between their intrinsic discourses at their home universities and contingent repertoire at the host university. As noted by Garry (male),

I already came back for 3 months, I have some deep experiences. For example, at the university, they have weekly routine meetings for scientific achievement and work reports. I feel this way actually is fairly good. Of course, we also have the rule in an interval time. But the frequency relatively is long such as one month. Therefore, the way can help orient students and instruct students timely. I feel it is remarkably useful for students.

He made a fraternal critique about "weekly routine meetings" with affirmative lexical items such as "fairly good" and "remarkably useful".

\subsection{Findings from Focus Group}

Focus group transcripts were analyzed for avoiding the researcher' fixed assumption and typical categories and giving participants more individual but collaborative spaces to generate emerging notions. In terms of the feasibility of drawing Canadian higher educational model into Chinese universities, the participants emerged with two adverse attitudes, i.e., partially agree and strongly disagree in light of their talks and forms of accounts. Meanwhile, they likewise came up with the underlying resistances. However, although most of the informants held a positive attitude about the feasibility mentioned, they still attempted to dilute their perspectives by using some symbolic lexis.

\subsubsection{Positive Attitude}

Seven professors expressed positive attitudes with relatively definite language regarding absorbing teaching models and even management ways of Canadian universities including teaching attitudes, teaching assessment, interactive teaching models, and encouraging students to come into contact with the society, and enhancing general education, and credit system. As Huang (female) said,

I contacted some professors in the Department of Industrial Engineering of the University of Regina in Canada and found that their teachings were very application-oriented. They pay attention to the cultivation of student practical abilities. For some mechanics courses, classroom teaching does not emphasize the derivation of equations but focuses on practical application. In fact, some universities in China have begun to change towards this direction. Nonetheless, the real integration is also influenced by other ineffable factors so if it is operated really, it is not easy. 
Huang appeared to celebrate the teaching idea that was learned at her host university. She felt it was more "application-oriented" and "practical", which suggested her intention to use the teaching idea in her teaching. However, she applied an adversative conjunction, i.e., "nonetheless" to indicate the difficulty of operation with some "ineffable factors".

Smile (female) mentioned as well,

This question is hard to answer. And I never think about it carefully. I feel no all can be feasible in Chinese higher education. But some could be introduced such as the credit system that already was operated in some Chinese universities. In terms of classroom teaching, the dialogical and interactive relationship between teachers and students also can be introduced but it cannot influence the process of fixed curriculum. Some slack ways, such as student's behaviors and dresses absolutely cannot be permitted in classrooms. Chinese teachers and tradition cannot accept the freestyle.

She used cognitive statements such as "I feel...", and some neutral sentences such as "the dialogical and interactive relationship between teachers and students also can be introduced but it cannot influence the process of the fixed curriculum", which suggested she affirmed the feasibility should be based on her traditional beliefs. She had a strong disagreement to "slack ways" of local students in class such as their behaviors and dresses that "absolutely" "cannot" appear in Chinese classrooms.

\subsubsection{Negative Attitude}

Three professors felt it was infeasible and unacceptable in undergraduate education and even graduate education to draw upon Canadian universities' model with negative lexical items (e.g. "impossible", "isn't necessary", "not feasible", "are not used to", and "not suitable"). Based on their discourses, the main resistances could be uncovered pertaining to macro social context (Chinese national situation), institutional resistance, normalized discourse formation ("the personnel cultivating program" and "fixed curriculum"), and disciplined power relationship between teachers and students, such as "students only keep silent", "don't know how they can talk" and "teachers don't have more autonomy to teach". As Hao(male) indicated, "higher educational improvement should be from governments to higher educational institution and teachers. It is impossible for teachers themselves to change current situation". Also, $W u$ mentioned that "the main duty of teachers is to teach the knowledge point regulated in given teaching outline and manage students strictly in class instead of changing teaching way and contents randomly." He utilized more constraining statements such as "main", "regulated", and "strictly". That is, as predicted, Chinese visiting professors were not only practitioners, but also conformists in their previous power relation (their home universities).

\section{Discussion and Conclusion}

Based on results from interviews and group discussion, it can be enunciated that offering an advance preparation for the successful transition of future Chinese international graduate students drawn upon these visiting professors' experiences is arguably restricted. The restriction is rooted in the three main factors, i.e., visit purposes and experiences of Chinese visiting professors, institutional resistances (Chinese national situation and inherent mechanisms in Chinese higher educational institutions), and Chinese pedagogical power relationship in which students merely are used to absorbing uncritically what is only the informed opinion of teachers instead of independent studies. Even so, from these visiting professors' narratives, it can also be unfolded that the advance preparation referred to above is partially feasible albeit the participants are influenced by their inherent discursive formation. This exactly embodies the contradiction that Chinese visiting professors exposed themselves to two distinct power relationships (Chinese and Canadian universities).

Soliciting visiting professor perspectives through focus groups guided by a specific question (i.e. is it feasible or not to employ Canadian universities' educational ideas to Chinese higher education) is an efficient method to make their statements more specific and individual. Precisely, in multiple aspects such as teaching attitudes, teaching assessment, interactive teaching model, seminar and public presentations, enhancing general education, and credit system, it is operative and referential in terms of graduate and even undergraduate education in Chinese universities. This not only verifies the results of interviews and the research hypothesis but also uncovers emerging themes.

\subsection{The Main Resistances}

\subsubsection{Visiting Purposes and Experiences}

As Parker (1992) said, "when there is attention to the dynamics of discourse linked to social structures this reflexivity can be grounded so issues of ideology and value become explicit" (p.40). In terms of visit purposes of participants, in most cases, the intention of improving teaching was located in a subordinate position compared 
with elevating academic skills and expanding academic fields, and family experience. Such situations more likely renders them to use continually their traditional teaching ways instead of making a reference to new teaching ideas in Canadian post-secondary institutions: "Social structure is a precondition for discourse"(Parker, 1992, p.40).Therefore, paying little attention to teaching mainly is due to two reasons including strict academic evaluation criteria for professional title promotion, i.e., three months or above visiting experience abroad and outcome evaluation in their home universities and solidified notion of Chinese parents in education. Most of the Chinese post-secondary institutions have used the traditional evaluation system of rewards and punishment to evaluate teachers. This evaluation system emphasizes quantification and quantifies teachers' teaching works and scientific researches. Moreover, this kind of evaluation system can easily make teachings and scientific researches become the means of teachers' promotion (He, 2012). In addition, Chinese parents have a higher expectation for their children so no one looks forward to their children losing at the start.

In their visiting experiences, as predicted, theywere experiencing the ambivalent situation that they generally held positive attitudes toward cultural contact, while language barriers impeded their academic and social contact, which more likely decreased the possibility that they would impart more positive overseas experience to their students.

\subsubsection{Institutional Resistances (Chinese National Situation and Higher Educational Mechanisms)}

"Discursive practices would be those that reproduce institutions, among other things." (Parker, 1992, p.17) That is, individual discourses in a given institution serve to sustain this institutional status. From the findings of interviews and group discussion, the informants' discourses implicated institutional resistances regarding an advanced preparation of potential Chinese international graduate students in Chinese universities. The overwhelming factor is the Chinese national situation. The undergraduate education in Chinese universities is not only a simple matter of accepting university education, but also a combination of employment opportunities and talent selection, maintaining social stability and rules. Therefore, it seems to be unsuitable for Chinese undergraduate education to draw upon Canadian higher education model. Moreover, the limitations of the fixed educational objective are apparent when it is to perform its functions in a curriculum (Eisner, 2001). As $W u$ signified, "the main duty of teachers is to teach knowledge regulated in given teaching outline and manage students strictly in class instead of changing teaching ways and contents randomly. Because the personnel cultivating program already is discussed and decided by experts so teachers cannot revise it". From his statement, one can imply an institutional restriction, namely: a set of fixed cultural values that mirrors the mainstream ideology.

\subsubsection{Chinese Pedagogical Power Relationship}

According to participants' narratives, they have been used to the most prominent form of instruction (i.e., the lecture) and traditional teaching ideas, i.e., teacher-led teaching and students' passive learning, and memory-based training and repeated skills. As Garry mentioned, “to me, it isn't necessary to follow them. I don't think that their way is the best. I think it is not feasible to adopt Western way during undergraduates and graduates because they are not used to this way." Hao also said, "it is useless because the subjects of teaching are students. We emphasize teaching but it is not functional and meaningless if students don't follow teaching despite various teaching methods. Students always doubt my teaching". It suggests that teachers and students have disciplined them into a traditional 'chalk and talk' method rather than one-on-one tutorial, group research programs, and group works.

\subsection{The Feasibility}

The feasibility of the transitive preparation of potential Chinese international graduate students before studying abroad also can be revealed by participants' discourses although the aforementioned resistances. From the finding of group discussion, it offered further for researching attitudes, experiences, and understandings of participants because "meaning production is a social and shared process" (Pickering, 2008, p.74). Firstly, opposing to the findings of interviews, most of the participants tended to have positive accounts and a relatively affirmative attitude to absorb partially Canadian university teaching model to their following teachings. Moreover, academics itself should be diverse rather than have a fixed answer although both educational models and cultures are derived from different ideologies. What is more, based on Chinese national situation and school situation, it is possible to make trial courses focusing on: (1) Application-based teaching mode. Actually, a few universities where some informants are working have begun to change towards this direction; (2) Interactive teaching model. Some participants have organized some trial seminars and other forms, and achieved positive results in a limited scale; (3) Encouraging student to contact with the society. In recent years, a few universities are bridging with enterprises so that students can understand the operative mechanism of enterprises; (4) Enhancing general education. The guiding principle of accreditation evaluation of the Ministry of Education is trending to general education in 
Chinese higher education that is stressed heavily in Canadian universities(Sun, 2012), which offers a policy support for the transitive preparation of potential Chinese international graduate students.

\section{Recommendations}

There are several possible recommendations focusing on how it is effective to draw upon these visiting professors' experiences and guide the transition of potential Chinese international graduate students in Chinese universities based on results of the current study.

The first recommendation is to employ a culturally relevant pedagogy. In this case, Pinar's method of currere can work to assist Chinese visiting professors to document narratives of their overseas experiences on their teaching practices in order to offer students cross-cultural atmosphere (Pinar, 2012).

The second recommendation is to encourage students to have an ethnographic inquiry. As mentioned above in the findings, these visiting professors experienced other unpredicted cultural barriers, which undoubtedly waters down their experiences. Therefore, these visiting professors should design trial courses that focus on helping students participate in cross-cultural experiences, attempting to understand other perspectives.

The third recommendation is to balance the two most prominent forms of instruction-the lecture and the seminar. Based on participants' narratives, a lecture has a dominant position in Chinese universities. Accordingly, visiting professors should try to frame some seminars, one-on-one tutorials, and public presentations to inspire students' critical thinking.

The fourth recommendation is that Chinese higher educational institutions should offer these visiting professors more flexible spaces to improve cross-culturally relevant pedagogy. Chinese higher educational institutions need to strategically view the visiting professors as an important resource for the internationalization of universities, providing more financial and policy support for them to improve cross-cultural teaching methods.

\section{References}

Agger, B. (1992). Cultural Studies as Critical Theory. Washington, DC: The Falmer Press.

Altbach, P. G., \& Knight, J. (2007). The internationalization of higher education: Motivations and realities. Journal of Studies in International Education, 11(3-4), 290-305. https://doi.org/10.1177/1028315307303542

Burton, F., \& Carlen, P. (1979). Official discourse: On discourse analysis, government publication, ideology and the state. London: Routledge and Kegan Paul.

Chao, C. G. (2016). Decision making for Chinese students to receive their higher education in the U.S. International Journal of Higher Education, 5(1), 28-37. https://doi.org/10.5430/ijhe.v5n1p28

Chinese Scholarship Committee. (2017). National professional senior research scholar, visiting scholar postdoctoral program column. Retrieved from http://www.csc.edu.cn/chuguo/s/1046

De Wit, H. (2002). Internationalization of higher education in the United States of America and Europe: A historical, comparative, and conceptual analysis. Westport, CT: Greenwood Press.

Eisner, E. W. (2001). What does it mean to say a school is doing well? Phi Delta Kappa International, 82(5), 367-372. https://doi.org/10.1177/003172170108200506

Galloway, F. J., \& Jenkins, J. R. (2005). The adjustment problems faced by international students in the United States: A comparison of international students and administrative perceptions at two private, religiously affiliated universities. NASPA Journal, 42(2), 175-187. https://doi.org/10.2202/0027-6014.1471

Gee, J. P. (1999). An introduction to discourse analysis: theory and method. London: Routledge.

$\mathrm{Gu}$, Y. (2006). An ecological model of e-learning in Chinese context-critical reflections of 5 years' practice of e-learning management in IBOE. Studies in Continuing Education, 28(2), 99-120. https://doi.org/10.4018/978-1-61520-749-7.ch008

He, W. (2012). Building a scientific and effective evaluation system of college and universitie teachers. Retrieved from http://www.1000thinktank.com/fmbd/4409.jhtml

Huang, L. H. (2015). Improving intercultural education at Chinese institutions from German experience. Journal of International Students, 5(2), 201-203. Retrieved from https:/files.eric.ed.gov/fulltext/EJ1060109.pdf

Jiao, J. (2006). Exploring the reasons for student ethnic groupings: The case of Chinese students at the of Chinese students at the University of Windsor (Master's thesis, University of Winsor, Ontario, Canada). Retrieved from https://scholar.uwindsor.ca/cgi/viewcontent.cgi?referer=https://www.google.com/\&httpsre $\operatorname{dir}=1 \&$ article $=7942 \&$ context $=$ etd 
Knight, J. (2003). Updated internationalization definition. International Higher Education, 33, 2-3. https://doi.org/10.6017/ihe.2003.33.7391

Knight, J. (2008). Higher education in turmoil. Rotterdam, Netherlands: Sense Publishers.

Kuo, B., \& Roysircar, G. (2004). Predictors of acculturation for Chinese adolescents in Canada: Age of arrival, length of stay, social class, and English reading ability. Journal of Multicultural Counselling and Development, 32, 143-154. https://doi.org/10.1002/j.2161-1912.2004.tb00367.x

Li, W. D., \& Chen, S.S. (2017). Acculturation strategy, integration paradoxes and educational adaptation-a case study of Chinese visiting scholar's family in the United States. International Education Studies, 10(9), 39-53. https://doi.org/10.5539/ies.v10n9p39

Liang, S. X. (2003). Academic adaptation: Mainland Chinese students in graduate programs at a Canadian university (Unpublished Doctoral dissertation). Graduate Division of Educational Research, Calgary, Canada.

Ortiz, A., Chang, L., \& Fang, Y. (2015). International Student Mobility Trends 2015: An Economic Perspective, Social Science Research Network. Retrieved February 2, 2018, from http://wenr.wes.org/2015/02/international-student-mobility-trends-2015-an-economic-perspective/

Parker, L. (1992). Discourse dynamics: critical analysis for social and individual psychology. London: Routledge.

Pickering, M. (2008). Research methods for culture studies. Edinburgh: Edinburgh University Press.

Pinar, W. F. (2012). What is curriculum theory? New York, NY: Routledge. https://doi.org/10.4324/9780203836033

Sam, D. L. (2001). Satisfaction with life among international students: An exploratory study. Social Indicators Research, 53, 315-337. https://doi.org/10.1023/A:1007108614571

Savin-Baden, M., \& Major, C. H. (2013). Qualitative research: the essential guide to theory and practice. New York: Routledge.

Shimmi, Y. (2014). Experiences of Japanese Visiting Scholars in the United States: An Exploration of Transition (Doctoral dissertation). Available from ProQuest Dissertation \& Theses: Full Text (UMI 3616035).

Statistics Canada. (2016). Study in Canada. Government of Canada: Ottawa, ON. Retrieved from http://www.canadainternational.gc.ca/china-chine/study-etudie/index.aspx?lang=eng

Statistics Canada. (2018). Canadian postsecondary enrolments and graduates, 2016/2017. Retrieved from https://www150.statcan.gc.ca/n1/daily-quotidien/181128/dq181128c-eng.htm

Sun, C. H. (2012). A new round of undergraduate teaching evaluation: from resources to outcomes. Retrieved from http://news.sciencenet.cn/htmlnews/2012/6/265803.shtm.

Sun, Y. (1987). An EFL needs assessment: Chinese students at a Canadian University. TESL Canada Journal, 5(1). https://doi.org/10.18806/tesl.v5i1.513

Talja, S. (1997). Constituting "information" and "user" as research objects: a theory of knowledge formations as an alternative to the information man-theory. ISIC '96 Proceedings of an international conference on Information seeking in context (pp. 67-80). Retrieved from https://dl.acm.org/citation.cfm?id=267194

Tannen, D. (2012). Discourse Analysis-What Speakers Do in Conversation. Retrieved from https://www.linguisticsociety.org/resource/discourse-analysis-what-speakers-do- conversation

UR international. (2018). Statistics. Retrieved from https:/www.uregina.ca/orp/assets/statistics/fact-brochures/ campus-facts-fall-winter-2017.pdf

Wotherspoon, T. (2014). The sociology of education in Canada: critical perspectives. Ontario: Oxford University Press.

Xue, M., Chao, X., \& Kuntz, A. M. (2015). Chinese visiting scholars' academic socialization in US institutions of higher education: a qualitative study. Asia Pacific Journal of Education, 35(2), 290-307. https://doi.org/10.1080/02188791.2013.876389

Yang, L. X. (2010). Doing a group presentation: negotiations and challenges experienced by five Chinese ESL students of commerce at a Canadian university. Language Teaching Research, 14(2), 141-160. https://doi.org/10.1177/1362168809353872 
Yatsko, V. (2013). Computational Linguistics Laboratory. Retrieved from http://yatsko.zohosites. com/integrational-discourse-analysis-conception.html

Zhang, Z. H., \& Zhou, G. (2010). Understanding Chinese International Students at a Canadian University: Perspectives, Expectations, and Experiences. Canadian and International Education, 39(3), 43-58.

Zhao, N. X., \& McDougall, D. (2008).Cultural influences on Chinese students' asychronous online learning in a Canadian university. Journal of distance education, 22(2), 59-80. Retrieved from https://files.eric.ed.gov/fulltext/EJ805078.pdf

Zheng, X., \& Berry, J. W. (1991). Psychological adaptation of Chinese sojourners in Canada. International Journal of Psychology, 26(4), 451-470. https://doi.org/10.1080/00207599108247134

Zhou, Y. Y. (2018). The impact of Chinese students in the US, charted and mapped. Retrieved from https://qz.com/1410768/the-number-of-chinese-students-in-the-us-charted-and-mapped/

\section{Copyrights}

Copyright for this article is retained by the author(s), with first publication rights granted to the journal.

This is an open-access article distributed under the terms and conditions of the Creative Commons Attribution license (http://creativecommons.org/licenses/by/4.0/). 